\title{
Professional Development with Follow-up for an Effective Paradigm Shift
}

\author{
Fehmida Goderya-Shaikh \\ Notre Dame Institute of Education, Pakistan
}

\begin{abstract}
The importance of transferring learning from a professional development programme is widely acknowledged. The problem lies in overcoming the mitigating factors and promoting the enabling factors that ensure transfer of learning by the teachers and educational leaders in the classrooms and schools. When transfer is successful school students are motivated that culminates in quality education for students. In addition, the teachers and educational leaders review and re-evaluate their own understanding and experiences taking on the path of continuous professional development. The findings of this study are important for planners of professional development programmes say for enhancing skills of teachers in the $21^{\text {st }}$ century. A case study approach was used with data collated from documents, in-depth interviews, observations, questionnaires and focus group. The findings through inductive analysis are that intensive followup, feedback and feed forward are required to support teachers to transfer their learning into the classrooms in both short term and long term professional development.
\end{abstract}

\section{Introduction}

Professional development of individuals in all walks of life, be it engineering, nursing, administration or teaching is acknowledged to promote growth and renewal. For growth and renewal to be sustainable professional development has to be continuous and a career long process. A continuous and a career long process of professional development can occur in two ways: 1) when individuals are self-directed and take an active role in their own professional development through reflection on practice; 2) providing new experiences to individuals that cause them to re-evaluate their knowledge. In the context of teacher professional development, skills knowledge and values are renewed at different career stages in their professional lives. Different forms of professional development programs exist such as workshop based which may be of short duration (for a day or a few weeks) or longer term professional development activities (for several months). This paper elaborates the results of a professional development activity that supports the theory that follow-up and feedback leads to transfer of learning in the school classrooms in two provinces of Sindh. The study suggests that additional feedforward cements the transfer of learning ensuring sustainability.

\section{Problem Statement}

The lack of transfer of learning in the classrooms is of concern to organizers of professional development programs. The teachers who undergo professional development activity often do not apply their learning in their classrooms after the completion of the programme. Thus, the problem statement is - what enabling factors promote teachers transfer of learning into the classroom from professional development programmes.

\section{Research Rational}

A research into the impact of a professional development activity from 2004 and 2007 in two districts of Sindh Province led to the results that form the genesis of this study. Although, the professional development was in four Sindh districts for government primary school teachers in pedagogical skills and content enhancement in science, mathematics, social studies and the languages, this study reports the findings in reference to two districts.

The study is important because the quality of education in Pakistan needs improvement [1]. Quality teachers need quality educational leaders who are well equipped to bring positive change within the school system [2]. Therefore, this study is significant as its findings may provide alternative structures and strategies towards improving the quality of professional development programmes within the Pakistani context.

This research is also significant as it seeks to contribute to the body of knowledge in educational research related to the impact of teacher education programmes in developing countries especially in Pakistan. The results can also be compared to similar research in other developing as well as developed countries. The study will also inform future 
educators, researchers, and educational authorities about the benefits of follow-on support after professional development programmes for teachers in Pakistan.

\section{Background}

Beginning with the background of the study, a perceived lack in the quality of education in Pakistan [3], in the primary sector of education $[4,5,6]$ led to education reforms programs [7] part of which required training of teachers. Researchers $[6,7,8,9]$ state that quality of education improves with professional development of teachers as through further education their knowledge is updated, skills are enhanced and their attitudes undertake a positive change.

Professional development authors [10,11,12,13] acknowledge that the success and sustainability of a professional development program is dependent on the effectiveness in changing the mind-sets of teachers, head teachers and administrators who are reluctant to change their ingrained practices and beliefs. Thus, the successful PDPs are able to develop a reflective teacher, head teacher or an administrator who constantly analyses his/her individual and collective strengths and weaknesses to bring about a positive change in their practices.

The UEI-PDP was a consortium of government, non-government and private educational institutes that came together to enhance the pedagogical skills and content knowledge of teachers, head teachers in the four districts of Sindh province, Pakistan. The PDP comprised of pedagogical enhancement at the training centres (TC) of two weeks, followed by field work of four weeks for teachers, return to TC for further content knowledge enhancement of two weeks that concluded with an intensive follow-up of ten weeks where the teachers implemented what they learnt at the TCs in their classrooms. For the head teachers and administrators, the first theoretical part of the PD was of four weeks that consisted of an awareness of the PDP for teachers with skill development in creating action plans, followed by two weeks of field work and a second theoretical portion of four weeks that included understanding concepts of collaboration and administration. Thus, total duration was eighteen weeks of PD for teachers and ten weeks for head teachers and administrators.

\section{Methodology}

The study adopts the epistemological framework of constructivism as the most appropriate to understand the meanings that are associated with the United Education Initiative-Professional development Programme (UEI-PDP) by the participating teachers, head teachers, administrators, school support team and master trainers. The shared perspectives include the UEI-PDP which brought the participants together. Focusing on the meaning and understanding from the participants' perspective is intended to give a rich description of the impact of UEI's PDP in shaping the teachers and head teachers as change agents in the learning and teaching environment in primary schools in Sindh Province, Pakistan. Equally important are the changes brought about by the UEI-PDP in the professional and personal lives of the teachers, head teachers and master trainers. How the change was achieved is an important contribution of this paper.

This study draws upon theoretical concepts of structural functionalism and symbolic interactionism [14]. In the school system there is the external administrative machinery of the District Education Authority (DEA) and the internal administrative machinery of the school system (the concept of structural functionalism where both the external and internal administrative machinery are part of a system that interact and affect each other's performance) which are interdependent for smooth functioning. The current research revealed that in the context of the UEI-PDP, in some districts the external and internal administrative machinery were coordinated and aligned with the same values and in others the linkages were weak.

According to the concept of symbolic interactionism the social life (in this study taken as the professional life) of people is formed, maintained or changed when they are constantly interacting and communicating with each other [15]. Linking this concept to the study, where observations and interviews revealed that in some schools, the head teachers (HTs) and primary school teachers (PSTs) worked collaboratively to achieve their own goals which were aligned with those of the UEI-PDP (symbolic interactionism) while in others the HTs and PSTs were discouraged by the external administrative machinery to implement their learning. Thus, symbolic interactionism has a distinct role in this study as explained.

The attribution of meaning by people to situations through symbols is a continuous process taking place in a social context, which, in this study was the school learning environment and the interaction of people (HTs, PSTs and SSTs) herein as well as at the Training Centre with the interaction of the MTs and PSTs during the teaching activities undertaken.

The research methodology defines the activity of the research, how the research proceeds and how progress is measured. A multi-site case study approach was adopted as the methodology for this research. In this multi site case study, the research strategy focused on the impact of UEI-PDP on the lives of the participants who experienced the intervention. The study included analysis of documents and considered the perceptions of 
primary school teachers, head teachers and programme managers of the UEI-PDP in Sindh.

The approach of a multisite site case study was used with each site treated as a single case and the individual conclusions used as information to contribute to the whole study that was the UEI-PDP. The questionnaire method was selected because a majority of the participants in the study were scattered in different talukas (administrative divisions) in the district of Sindh. The 130 questionnaires were sent to 30 head teachers, 60 teachers, 20 master trainers (MTs), 11 members of the school support team (SSTs), 2 (assistant district education officers (ADEOs) and 4 supervisors comprised this study. As all the participants were based in schools, consent was requested from the participants by the semi-structured questionnaire. A letter was included with the questionnaire indicating the purpose of the research and the nature of their involvement in the research. The questionnaires were used to identify 6 schools whose teachers and head teachers were interviewed and observed and also led to the identification of prospective focus group participants.

The research was undertaken in three phases. In the first phase, the researcher began data collection by first contacting, MTs, SSTs and each head teacher of the school who could be under consideration for the study. The contact information was available from a data base maintained at UEI Office. The questionnaires were sent directly to individual MTs, SSTs and then collectively to the schools' head teachers who were requested to distribute the questionnaires to two teachers in their schools who had undergone the UEI-PDP. The criterion of experiencing the UEI-PDP was mandatory for all participants as the research was an impact study of the PDP. The deadline for return of questionnaires was given to ensure that the participants completed the questionnaires in time to give the researcher ample time to collate and analyse the data. Permission was sought from the head teachers of the schools to interview the teachers as well as observe the classrooms during the teaching - learning process.

The second phase of the study included interviews and observations and also identification of schools with a unique situation. Apart from the PSTs and HTs of schools, the SSTs, MTs and ADEOs were also interviewed to get a deeper understanding of support services provided in the teaching learning environment. According to Robson [16] the limitations of validity and reliability in case studies can be reduced by triangulation using different tools for collecting data such as documents, interviews and observations. This triangulation contributed to the validity and reliability of the study.

The third phase of the study ensured further triangulation of the data through two focus group interviews, one in each district. The individual interviews and focus group interviews were recorded and transcribed. It was the intention of the researcher that participants whose responses in the individual interviews revealed information pertinent to the research question would be invited to the focus group interviews. It was ensured that participants in the focus group interviews were able to participate without any hesitation by ensuring that there were no power relationships existing within the participants.

\section{Results}

Merriam [17] states that the qualitative approach of data analysis is highly intuitive as quite often it is difficult for researchers to state precisely how they arrived at their theory building or arrived at their conclusion from the information collected. However, according to Miles and Huberman [18] good data management, careful processing and analysis of the data can ensure that the researcher discovers emerging themes in the context of the research. Data collated and analysed through Document analyses, in-depth interviews, questionnaires and focus group identified common themes such as relevance of the designed curriculum for the PDP, change in attitudes of those who experienced the intervention, enabling and mitigating factors.

\subsection{Document analyses}

The UEI-PDP documents were analysed using an inductive approach that included overlapping analysis with data collection [19]. Initial data collection and analysis began with the information deciphered from the documents maintained at the UEI office. Some of the documents were in hard copies and soft copies of other documents such as reports were also available. The confidentiality of the participants in this study is maintained by using their position rather than their names (that is whether the reports were made by program managers, MTs, SSTs or the MandE officers).

The United Education Initiative (UEI) was a product of the government's initiative to encourage public-private partnership where five organizations pooled their resources together. UEI believed in improving the quality of education for the masses through a partnership with other educational organizations; by setting up viable institutional structures that focused on planning, implementing and assessing educational activities. Education sector reform assistance [20] was the agency that delegated the implementation of the teacher training component to the UEI consortium. This consortium was formed to implement a part of an educational reform program that included the training of teachers, head teachers and educational 
administrators in addition to other objectives [7]. The educational reform was drawn from the millennium development goals [21] that have human development as one of its objectives.

An insight into the emerging themes is presented in the following subsections.

6.1.2. Curriculum relevance. The focus of the study was on two of the modules as these modules were believed to be innovative experiences for the teachers. The modules are 'Reflective practice' and 'Mentoring and peer coaching'. The impact of these modules was studied through the questionnaire which was distributed to the participants. Documentary evidence of the MTs and course participants (CPs) perceptions of the modules were:

a) The responses for the pedagogy (teaching methods) used at the TC:

1. MTs: The methods used to teach the concepts in the module were activity based according to the MTs. They used the lecture method with additional questions to involve the participants, think-pairshare, jigsaw strategies, cooperative learning strategies, silent reading, reading aloud and role plays.

2. PST-CPs: "Teaching our students in the classroom was made easier when we used the same methods that were modelled to us by the MTs. Just like we were always actively involved in learning and keen to know what new concept we would learn next our students had a similar experience."

b) The responses for contextualising the curriculum that was implemented:

1. MTs: They simplified terms and activities to make it according to the context of the teachers in the initial stages of the training. The modules of Reflective practice and Mentoring and peer coaching were affirmed to be an interesting concept and relevant for the PDP as it was new for the teachers, head teachers and administrators. They paired up participants who were experiencing difficulty in the training with those who were not.

2. PST-CPs: Stated examples of now reflecting and sharing with their peers their problems encountered while teaching, which they were reluctant to do before the completion of the module at the training centre. Before the training, the CPs practice within their teaching was to seat the slow learners at the back of the classroom but now they pair-up the slow learners with other students. The teachers also now ensured that the slow learners are seated so that the teachers can easily approach them and give the students individual attention when required.

3. MTs for HTs: According to the MTs responses the head teachers were also trained on the importance of embedding the reflective practice into their daily work routine. The MTs demonstrated the importance of working in a collegial atmosphere, the advantages of holding frequent meetings with parents and teachers. The head teachers were encouraged to change from their autocratic practices and adopt democratic practices by involving the teachers in discussions and take their opinions when making academic decisions.

4. HTs-CPs: Prior to the training program the belief of the head teachers was that if they consulted with their teachers on decision making, their teachers would think that the head teachers did not know how to perform their duties. Another essential learning for the HTs during the UEI-PDP was the importance of having meetings with the community members who could then be encouraged to contribute, through their knowledge and skills (or through monetary means) in improving the teaching learning process in schools.

5. SSTs: They stated that they learnt how to mentor and support teachers in a friendly manner and not like an inspector which was their earlier practice. They were particularly satisfied with the modules of reflective practice, mentoring and peer coaching and teaching through media. With particular reference to reflective practice they stated that this was helpful not only professionally but also in their daily life as they were able to find solutions to their problems.

6. PSTs-CPs: According to their statements: "In the first field work of ... weeks the SSTs would guide us on how to incorporate different activities when preparing a lesson. When we returned to the training centre then we would discuss with the MT what we had tried out and the difficulties experienced. During the second field work phase the SSTs visits in the schools and discussions helped us to clarify our understanding of how to use different teaching methods with different subjects and prepare relevant teaching aids using low cost materials."

6.1.3. Change in attitudes. Documents indicated that during the course of the UEI-PDP there was an observable change in attitude of the PSTs and HTs in the following context (that is: punctuality, participation, sharing of ideas and volunteering) because at the beginning of the training the CPs did not:

- come on time to the TC but now arrived on time

- participate actively during the training session but now participate actively

- share their thoughts but now share ideas without hesitation

- volunteer to come to the front and present their work but now they do

6.1.4.Enabling and mitigating factors. According to the documents the enabling factors in transferring the learning for each of the different categories of participants (that are: MTs, PST-CPs, HT-CPs, SSTs) varied. For the MTs, it was being able to change the attitude of the CPs to the UEI-PDP by 
making the sessions interactive and interesting as well as involving the CPs in critical reflections where they discussed their earlier knowledge and practices and compared them with what they had now learnt. Feedback from SSTs and PSTs after the first field work on difficulties experienced in the field enabled the MTs to give a feed forward.

For the PST-CPs, the enabling factors that helped them to transfer their learning into the classrooms were the meetings with SSTs (in the field) and MTs (in the TCs). These meetings and dialogue helped to clarify their understanding of how they were to implement student-centred learning in the classrooms and eased the initial adaptation issues - for instance, after the first two weeks of training a teacher stated her concern, of whether "Will I be able to teach using group work - I have never used this method before - and, how will I manage the class?”

Other enabling factors for the PSTs-CPs and HTCPs were:

"Discussing with head or colleagues when we have an issue"

"Students are enjoying activities; we want to use what we learnt"

"Students attendance is improving, and teachers are working together so we are enjoying teaching." "Follow up provided by SSTs where they guided teachers in lesson planning, collecting material for use in preparing of low-cost teaching aids"

"The discussions with SSTs and MTs on the problems in implementing some activities due to lack of space or electricity failure, change that was being experienced in the schools and how to promote it further."

The SSTs stated that "The follow-up that we provided helped us to show teachers how to organise group work and make low cost teaching aids."

Some mitigating factors according to the SSTs, as stated by their CPs, were: Firstly, the number of students in the classroom which made provision of resources for the students difficult and this was because most of the students could not afford to purchase resources such as charts, colours and so on. Secondly, the large number of students in the class with unmovable furniture also challenged the organisation of group work. Thirdly, the visits by supervisors (not involved in the training and so did not appreciate the advantages of student-centred teaching) who as per their traditional beliefs that a quiet class meant the students were studying and if the notebooks were filled then that implied the students had learnt and understood the topic.

\subsection{Interviews and observations}

Data collated and analysed through interview and observations are in the following subsections.
6.2.1. Curriculum relevance and change in attitudes. All the interviewees were adamant that the PSTs and HTs behaviour and attitude had changed for the positive during the course of the program but they had their doubts on the sustainability of the change after the completion of the program. The MTs, SSTs and program managers expressed their concern as the issue of ownership of the UEI-PDP by the DEO. This concern was rightly expressed as visits to the schools where the ADEO had their office (schools UHCb and $\mathrm{UTKb}$ ) revealed that they discouraged group work as wastage of time and emphasized on filling of the notebooks by the students as evidence that teachers had done their duty of teaching the students. A different situation was observed in a high impact school (UHCg) where the ADEO had her office who also wanted to have the notebooks filled by the students but did not interfere in the school teachers' instructional procedures. It can be interpreted as personal characteristics and beliefs of the DEO would affect the transfer of learning by the PSTs and HTs in the schools.

The PSTs and HTs asserted and made attempts to convince the researcher that they had never before experienced any training where they were involved in group work, called forward to give presentations and guided "so positively", always encouraged irrespective of whether or not the given answers were correct.

6.2.2 Enabling (E) and mitigating (M) factors. The data collated from the in-depth interviews of the PSTs and HTs corroborate the findings from the documents. The individual statements are followed by (E) indicating enabling factor or $(M)$ as the mitigating factor and then the school and teacher code.

1, PSTs-CPs: "Visits by SSTs helped me to do activities with students in lessons" (E). RTGg-T1

"Do not hesitate to ask a colleague now but never before" (E). UTKb-T1

Meetings, discussions with MTs, SSTs, HTs and PSTs help” (E). RTGg-T2

"Having colleagues and a head teacher who supports is very good" (E). UHCg-T2

"Our head encourages us to use different teaching methods (E) but the supervisors think that we are wasting time by not getting students to write in their books" (M). UHMg-T2

"The supervisors need to support us. Sometimes when they visit and find us doing group work they discourage us from it, saying that it is a waste of time” (M). UHMg-T1

"Need recognition from the government for our work” (M). UTKg-T2

2. HTs-CPs: "SSTs helped teachers to plan lessons with group work for students” (E). RTGg-HT 
"We are trying our best (E) to do what we can in the resources that we have.” UTKg-HT

"Learnt new teaching methods, reflect and prepare action plans (E). RTGb-HT

"I have improved in my management skills and I consult my teachers frequently so that they are also involved in decisions" (E). UHCg-HT

"Working as a HT is easier now I know what to do administratively” (E). UTGg-HT

"The DEA has to support our different ways of teaching and encourage the teachers by praising them for trying new things" (M). UHMg-HT

The statements by the participants indicate that in some schools the internal and external administrative machinery were aligned with common understanding and goals whereas in other schools the contrary situation existed.

\subsection{Questionnaires and Focus group}

The findings from the documents, interviews and observations were corroborated with the questionnaires and focus group. The enabling and mitigating factors according to the perspectives of the PSTs, HTs, SSTs and MTs are enunciated.

a) Perspectives of PSTs

Enabling factors:

The follow-up by the SSTs was stated to be one of the determinant factors that helped to make the PSTs put the theory learnt at the TC into practice. As stated by a PST, "Teaching has become easier and I enjoy it now.”

\section{Mitigating factors:}

Two PSTs stated that the ADEOs need to provide more support to facilitate the teachers and not to 'discourage' the teacher from organising group work. The same comment was made by a number of the PSTs in their questionnaires while some abstained from answering the associated questions. This implies that the PSTs were not satisfied with the ownership and support of the program by the ADEOs. The supervisor who was interviewed did not want to comment, which could be linked to uncertainty of retribution. Some relevant written statements by PSTs and HTs in the questionnaires were: 'the education system can improve if the District Education Department provide support,' 'support should be in form of verbal encouragement,' 'provide teaching aids,' 'not to involve teachers in non-academic work,' and 'when we are asked about what we are doing with the students in the classrooms we are motivated.'

PSTs also stated that 'there should be some reward and consequence mechanism to motivate teachers to apply their learning after undergoing PD.' A number of PSTs stated that they were de-motivated when the term for their follow-up support by the SSTs came to an end. They wanted the support to continue instead of stopping after some months. Thus, the motivating factor was the continuous support provided by SSTs.

b) Perspectives of HTs

Enabling factors:

A comment on follow-up support by a head teacher, 'I like the follow-up done by the SSTs - their coming into the schools to help the teachers brought about the change that you see' (In-depth interview UHMg-HT, FG-H and FG-T).

Another comment on the training received with regard to planning - "I am better prepared and can plan ahead."

With reference to ownership a head teacher commented that "involving teachers in decisionmaking process gives them a feeling of ownership."

Mitigating factors:

As stated by a head teacher "when supervisors complain that the copies are not filled and the syllabus is not complete then it de-motivates teachers (and me) from organising different activities and group work for the students.”

\section{c) Perspectives of SSTs}

Enabling factors: Statements by SSTs such as:

"Teachers who are enthusiastic and want to try new things when they are teaching." This shows that the attitude of the teachers is important.

The motivating factor was a change in the learning environment indicated by the comment "The change in the learning environment where you see students work displayed in the classrooms and teachers making teaching aid with clay.”

"Supportive HTs who ensure that the PSTs get the materials required for learning and teaching process."

Mitigating factors:

"When teachers tell us that the supervisors have asked the teachers to rearrange the desks in the class from group arrangement into row arrangement."

"The distances to some schools which make it difficult to provide maximum support."

"The political influence of some teachers who do not want to change and try new things - they also discourage other PSTs from applying new learning."

\section{d) Perspectives of MTs}

Enabling factors: CPs who are keen to learn and participate actively in all teaching learning activities. Another enabling factor for MTs was "meeting other colleagues and learning their best practices.”

Mitigating factors:

"When politically motivated CPs try to disrupt teaching and learning processes in the TC through unnecessary delaying tactics and arguments." 


\section{Conclusions}

From the aforementioned statements and comments by the participants in the UEI-PDP it is argued that there was a change in attitude had occurred, knowledge and skill enhancement had also taken place. This human development had occurred due to the follow-up that was an integral part of the design of the program with continuous feedback and feed forward provided by all the stakeholders involved in the UEI-PDP.

The change in attitude is as a result of the teaching methods, modules and the frequent meetings between the MTs and PSTs. The meetings helped to ensure that the course participants were given the opportunity to voice the difficulties faced when applying the theory learnt (at the TC) into practice when the participants were in the field. The sharing of field experiences, both negative and positive, provided an insight to the MTs on the further needs of the PSTs with regard to PD activities. Similarly, meetings (part of the follow-up visits) between the SSTs and PSTs in the field helped the PSTs to put into practice the theory learnt and also in preparing appropriate low cost teaching aids. Reflective dialogue cleared misunderstanding or even sharpened their understandings of the pedagogy and content learned. Forums were organised within districts where selected participants gathered to hear about teachers and head teachers' best practices. This motivated the participants in the UEI-PDP. Similarly, communicating with other teachers within their own district and having a dialogue with colleagues on how they solved particular problems, which were common, provided the CPs with additional exposure of solving problems within a different cultural or common context. Additionally having HTs as leaders who were supportive, encouraged sharing of ideas and collaboration amongst the teachers was an enabling factor to transfer learning in the classroom.

When the enabling factors were predominant the UEI-PDP was able to develop teachers and educational leaders to become self-directed looking for alternative solutions to improve education for the students in their schools. These teachers and educational leaders also collaborated to improve the learning and teaching processes by ensuring that both the internal and external administrative machinery were aligned with common goals.

Recommendations from the study are enumerated: (i) When planning the implementation of a PD activity, intermittent short term and long term follow-up strategies of the participants should be incorporated into the plan. Short-term strategies such as meetings with the MTs, and SSTs support in the field. However, the long-term follow-up strategies were in the jurisdiction of the DEA. This shows that the DEA and the Provincial ministry (Sindh) need to ensure that all professional development programmes, irrespective of whether the government education departments are involved directly or indirectly in its implementation or with other NGOs or donor agencies, are followed-up frequently even after the end of the contractual period.

(ii) The amount and quality of follow- up support given to the participants by all the stakeholders results in sustainability of the changes in practice from transfer of learning through PD activities. The stakeholders in this context are the MTs, SSTs, MandEs, PM, ADEOs, supervisors, DEA. In the UEI-PDP from 2004 to 2006 the follow-up support was provided to all participants by MTs, SSTs, MandEs and PM.

(iii) The follow-up can be given by the trainers and by DEAs involved in the intervention including researchers. The importance of follow-up cannot be more emphasised than by reiterating to establish a PD forum at both the District and Taluka levels that comprise of members of the DEA, District Governance and the educated fraternity of the community with selected PSTs and HTs. This may carve the path to promote a self learning environment for the community, teachers and the education department. Such a model established during the extension phase if adopted by the Provincial Education and Literacy Department (Sindh) will provide a culture of continuous professional development similar to the school based professional development created and researched in Australia, England and United States.

Ensuring that collaborative structures are organised, which are of long duration, to ensure follow-up, feedback and feed forward will support transfer of learning from any professional development programme. The need of $21^{\text {st }}$ century teachers is computer literacy with the knowledge and skills of integrating computers into the teaching and learning process. Currently, the observations and findings from this study are seen implemented in another knowledge and skill enhancement program for Faculty members of Government Elementary College of Education (where the author is involved). The faculty members are involved in piloting the new Associate degree of Education which is the first two years of a four year Bachelors in Education (honours) study implemented by Pre-service teacher education program [22]. Professional development and follow-up support are provided to the faculty members on enhancing their pedagogical skills, assessment practices and computer literacy. It is hoped that the feedback and feedforward through the follow-up will develop educational leaders who are committed to improving the quality of education in Pakistan. 


\section{References}

[1] P. Hoodbhoy, "Pakistan's education system its greatest threat.,”2004;http://www.Pakistan-

facts.com/article.php/20041017195851719. (10 January 2006)

[2] T. Simkins, V. Garrett, M. Memon, and R. Nazir-Ali, "The role perceptions of government and non-government head teachers in Pakistan”, Educational Management and Administration, 26(2), 1998, pp. 131-146.

[3] UNESCO, "Situation analysis of teacher education: Towards a strategic framework for teacher education and professional development.,"2006;

http://www.scribd.com/doc/8544591/FINAL-Situation-

AnalysisStrategic-Framework-for-Teacher-Education. ( 27 December 2010)

[4] I. Farah, S. Ali, and A. Siddiqui, "Pakistan country review of access to primary education," Aga Khan University, Institute for Educational Development, Karachi, 2006.

[5] M.K. Jalalzai, The crisis of education in Pakistan: state education and the text-books, Al-Abbas International, Lahore, 2005.

[6] Mahbub-ul-haq Human Development Centre, "A ten year review of state of education in Pakistan," Human Development in South Asia 2007 Oxford University Press, Karachi, 2007, pp. 144-155.

[7] Ministry of Education, "Education sector reforms action plan 2001-02 and 2005-06," Government of Pakistan, Islamabad, 2004.

[8] M. Fullan, "Leading in a culture of change," JosseyBass, San Francisco, 2001.

[9] A. Hargreaves, "Development and desire: A post modern perspective," Professional development in education: New paradigms and practices, T.R. Guskey, and M. Huberman eds., Teachers College Press, New York, 1995, pp. 9-34.

[10] K. Hammerness, L. Darling-Hammond, J. Bransford, D. Berliner, M. Cochran-Smith, M. McDonald, and K. Zeichner, "How teachers learn and develop," Preparing teachers for a changing world, L. Darling-Hammond, and J. Bransford eds., Jossey-Bass, San Francisco, 2005.

[11] M. Fullan, and A. Hargreaves Teacher development and educational change, Routledge, London,1992.

[12] T.R. Guskey, "Professional development in education: in search of an optimal mix," T.R. Guskey, and A.M. Huberman eds., Teachers College Press, New York, 1995, pp. 114-131.

[13] B. Joyce, and B. Showers, Student achievement through staff development, Longman, Harlow, 1988.
[14] L.N. Neuman, Social research methods:Qualitative and quantitative approaches, $3^{\text {rd }}$ ed., Allyn and Bacon, Needham Heights, 1997.

[15] L. Stoll, and D. Fink, Changing our schools, Open University Press, Buckingham, UK, 1996.

[16] C. Robson, Real world research, Blackwell Publishing, Malden, USA, 2002.

[17] S. B. Merriam, Qualitative research and case studies applications in education, Jossey-Bass, San Francisco, 1998.

[18] M. B. Miles, and A.M. Huberman, Qualitative data analysis, SAGE, Thousand Oaks, 1994.

[19] K. M. Eisenhardt, "Building theories from case study research," Academy of Management Review, vol. 14, no. 4, 1989, pp. 532-550.

[20] RTI International, ESRA Quarterly Progress Report No. 9, RTI International, Islamabad, 2005.

[21] F. Goderya-Shaikh, "Meeting the millennium development goals-through the lens of a PDP," Paper presented at 2nd International Conference of University of Education, Lahore, September 22-24, 2010

[22] Pre-STEP, "Pre-service teacher education program," http://www.edc.org/projects/pre-service_teacher_ education_program_pre-step (28 December, 2010) 